underlying obstetric complications and therefore reflects the additional risk of the procedure itself.

The ratio of severe maternal morbidity to mortality has been suggested as a possible new indicator of quality of maternal care. While this approach could be useful in allowing comparisons between different centres, interventions, and approaches to care, it is important that this does not result in league tables that fail to take account of differences in the risk profile of the populations served.

This paper moves forward from an evaluation of obstetric care purely in terms of mortality and admissions to intensive care. We will undoubtedly see refinements to the definitions and more innovative approaches to the ascertainment of difficult outcomes such as thromboembolic disease and amniotic fluid embolism. It provides a useful template on which to plan comparative studies in other populations with the potential to focus on issues relating to health inequality, place of birth, mode of delivery, and the effectiveness of practice guidelines.

1 Department of Health. Report on confidential enquiries into maternal deaths in the United Kingdom 1994-1996. London: Stationery Office, 1998.

2 Fitzpatrick C, Halligan A, McKenna P, Coughlan BM, Darling MRN, Phelan D. Near miss maternal mortality (letter). Irish Med J 1992;85:37.

3 Drife JO. Maternal "near-miss' reports? BMJ 1993;307:1087-8.

4 Tuffnell DJ, Johnson H. Amniotic fluid embolism: the UK register. Hosp Med 2000;61:532-4.

5 Campbell R. Review and assessment of selection criteria used when booking pregnant women at different places of birth. BrJ Obstet Gynaecol 1999;106:550-6.

\title{
Increasing prevalence of obesity in primary school children: cohort study
}

\author{
Mary C J Rudolf, Pinki Sahota, Julian H Barth, Jenny Walker
}

Community

Paediatrics, Leeds Community and Mental Health

Trust, Leeds

LS2 9NP

Mary C J Rudolf

community

paediatrician

School of Health

Sciences, Leeds

Metropolitan

University, Leeds

LS1 3HE

Pinki Sahota

senior lecturer in

nutrition and dietetics

continued over

BMJ 2001;322:1094-5

\section{bmi.com}

This article is part of the BMJ's

randomised

controlled trial of

open peer review.

Documentation

relating to the

editorial decision

making process is

available on the

$B M J$ 's website
Reports suggest that the prevalence of obesity among children is increasing. Reilly et al reported that, even by the age of 5 , the prevalence of obesity was higher than that expected from the national standards ${ }^{1}$ and that this persisted into the teenage years. ${ }^{2}$

\section{Participants, methods, and results}

From 1996 to 1999 an auxologist (JW) measured children in 10 primary schools in Leeds participating in a health promotion programme. ${ }^{3}$ Children in years 3 and 4 (age 7-9 years) were measured in July 1996 and again in July 1997 and 1998. These children were marginally more advantaged than average for Leeds, with $1-42 \%$ of pupils from ethnic minorities and $7-29 \%$ entitled to free school meals (a measure of social disadvantage).

Height was measured to $0.1 \mathrm{~cm}$ with a free standing Magnimeter stadiometer (Raven, Dunmow). Weights were recorded to $0.1 \mathrm{~kg}$ without shoes or jumpers. The mean of three triceps measurements was taken. ${ }^{4}$ Body mass index (weight $(\mathrm{kg}) /\left(\right.$ height $\left.(\mathrm{m})^{2}\right)$ ) was calculated and converted to standard deviation scores using the revised 1990 reference standards ${ }^{5}$ and the Tanner Whitehouse (1975) standards for skinfold thickness. ${ }^{4}$ The following conventional cut-off points were applied: body mass index standard deviation score greater than 1.04 (85th centile) for overweight and greater than 1.64 (95th centile) for obesity. Using these definitions the expected percentages were $15 \%$ for overweight and 5\% for obesity, relative to British children in 1990. Observed levels were compared with expected levels using $\chi^{2}$ goodness of fit test.

All but 21 children agreed to participate. Overall, 608 children were measured in 1996, 540 in 1997, and 499 in 1998 (some of whom were not measured in 1997). In addition 86 new children joined the study in 1997 and 1998. In total 694 children were measured, resulting in 1762 measurements.

The table shows the proportion of children with body mass index and triceps measurements above the 85th and 95th centiles according to age. A significant increase in the proportion of overweight and obese children was observed in those aged 9, 10, and 11 years.

\section{Comment}

A noticeable increase in the prevalence of obesity has been observed such that one in five 9 year olds and one in three 11 year old girls are overweight. We collected new data on measurements of the skinfold at the triceps. Given the increase in the extent of body mass index these measures were surprisingly not significantly greater than those expected from the 1975 standards. Anecdotal evidence suggests that the 1975 standards were based on overweight children ( $T$ Coles, personal communication), and this may prove to be the

Body mass index scores and triceps skinfold measures in Leeds primary school children. Values are numbers (percentages) unless stated otherwise

\begin{tabular}{|c|c|c|c|c|c|c|c|c|c|c|c|c|}
\hline \multirow[b]{2}{*}{ Aget } & \multicolumn{6}{|c|}{ Girls } & \multicolumn{6}{|c|}{ Boys } \\
\hline & 7 & 8 & 9 & 10 & 11 & Total & 7 & 8 & 9 & 10 & 11 & Total \\
\hline Body mass index & $\mathrm{n}=22$ & $\mathrm{n}=162$ & $\mathrm{n}=261$ & $\mathrm{n}=230$ & $\mathrm{n}=112$ & $\mathrm{n}=787$ & $\mathrm{n}=30$ & $\mathrm{n}=192$ & $\mathrm{n}=320$ & $\mathrm{n}=280$ & $n=153$ & $\mathrm{n}=975$ \\
\hline Overweight & $3(14)$ & $24(15)$ & $56\left(22^{\star}\right)$ & $53\left(23^{\star *}\right)$ & $36\left(32^{\star \star}\right)$ & $172\left(22^{\star \star *}\right)$ & $3(10)$ & $25(13)$ & $71\left(22^{* \star}\right)$ & $70\left(25^{\star \star}\right)$ & $41\left(27^{\star \star *}\right)$ & $210\left(22^{* *}\right.$ \\
\hline Obese & $1(5)$ & $10(6)$ & $27\left(10^{\star \star *}\right)$ & $33\left(14^{* *}\right)$ & $15\left(13^{\star \star}\right)$ & $86\left(11^{* \star}\right)$ & $1(3)$ & $10(5)$ & $33\left(10^{* \star}\right)$ & $38\left(14^{\star \star}\right)$ & $30\left(20^{* *}\right)$ & $112\left(12^{* *}\right.$ \\
\hline Triceps & $\mathrm{n}=22$ & $\mathrm{n}=160$ & $\mathrm{n}=257$ & $\mathrm{n}=231$ & $\mathrm{n}=112$ & $\mathrm{n}=782$ & $\mathrm{n}=29$ & $\mathrm{n}=190$ & $\mathrm{n}=318$ & $\mathrm{n}=280$ & $\mathrm{n}=153$ & $\mathrm{n}=970$ \\
\hline Overweight & $3(14)$ & $26(16)$ & 39 (15) & $26(11)$ & $17(15)$ & $111(14)$ & $4(14)$ & $19(10)$ & $47(15)$ & $44(16)$ & $28(18)$ & $142(15)$ \\
\hline Obese & $1(5)$ & $5(3)$ & $11(4)$ & $8(4)$ & $4(4)$ & $29(4)$ & $1(4)$ & $9(5)$ & $22(7)$ & $13(5)$ & $5(3)$ & $50(5)$ \\
\hline
\end{tabular}

Prevalence of overweight and obesity is shown using definition of greater than 85 th centile for overweight and greater than 95th centile for obese.

Frequencies significantly different from expected values of $15 \%$ (overweight) and $5 \%$ (obesity) at ${ }^{*} P<0.01,{ }^{* \star} P<0.001$.

tEach year group was taken as year to next birthday ("seven" year olds included children aged 7 to less than 8 years). 
simple explanation. However, a larger study is required to establish new references. The latest British growth standards were developed in 1990, but less than a decade later it has become evident that these standards no longer reflect the distribution of weight in British schoolchildren.

The cause for concern is twofold. Firstly, cohort studies show that obesity may track from childhood to adulthood, where morbidity is very evident. Secondly, obesity in adolescence is directly associated with increased morbidity and mortality in adult life independent of adult body weight. This study lends further support to reports that levels of obesity in Britain are increasing at an appreciable rate in primary school children, that the measures of skinfold at the triceps need to be revalidated, and that this major public health issue needs urgently addressing in young children.

Contributors: MCJR was the principle investigator of the active programme promoting lifestyle education in school project. She conceived and designed the article, analysed and interpreted the data, and drafted the manuscript. She will act as guarantor for the paper. PS was the project manager of the active programme promoting lifestyle education in school project, analysed the raw data, discussed core ideas, and revised the article for intellectual content. JHB discussed the core ideas and edited the article. JW collected the anthropometric data and also discussed core ideas.

Funding: This research was supported by a grant from NHS Northern and Yorkshire Region Research and Developmen Unit. The Castlemead Growth Programme 1993, a software package produced by Castlemead, was used to analyse the body mass index and triceps data.

Competing interests: JHB has received consultancy fees from Roche Pharmaceuticals.

Reilly JJ, Dorosty AR, Emmett PM. Prevalence of overweight and obesity in British children: cohort study. BMJ 1999;319:1039.

2 Reilly JJ, Dorosty AR. Epidemic of obesity in UK children. Lance 1999;354:1874-5.

3 Sahota P, Rudolf MCJ, Dixey R, Hill AJ, Barth JH, Cade J. APPLES: a primary school based randomised controlled trial to reduce obesity risk factors. $B M J$ (in press)

4 Tanner JM, Whitehouse RH. Revised standards for triceps and subscapular skinfolds in British children. Arch Dis Child 1975;50:142-5.

5 Cole TJ, Freeman JV, Preece MA. Body mass index reference curves for the UK, 1990. Arch Dis Child 1995;73:25-9.

(Accepted 21 December 2000)

\title{
Age of menarche in contemporary British teenagers: survey of girls born between 1982 and 1986
}

\author{
P H Whincup, J A Gilg, K Odoki, S J C Taylor, D G Cook
}

The possibility that puberty is occurring earlier in Britain than previously has caused great interest. ${ }^{1}$ Despite the importance of menarcheal age as an indicator of puberty, ${ }^{2}$ there is little information on menarcheal age in contemporary teenagers to compare with data on girls born in the 1950s and 1960s. We report on the distribution of menarcheal age in a survey of British girls born between 1982 and 1986.

\section{Participants, methods, and results}

In 1998-9 we studied the cardiovascular health of secondary school children aged 12-16 in schools in 10 British towns: five in southern England (Esher, Leatherhead, Chelmsford, Bath, Tunbridge Wells), three in north west England (Wigan, Burnley, Rochdale), and two in south Wales (Port Talbot, Rhondda). We approached those secondary schools corresponding to a stratified random sample of primary schools in our earlier study ${ }^{3} ; 62$ of $65(95 \%)$ with female pupils participated. In each school we invited girls from the earlier study to participate, with a supplementary random sample of pupils from the same classes. ${ }^{3}$ During screening the girls completed a confidential self administered questionnaire on date of birth, whether they had started their periods and, if so, their age (years and months) at the first period. Social class was based on parental occupation (using the Registrar General's 1990 classification). Ethnicity was based on appearance and cross checked with surname and parental self assessment. We used SAS (version 6.12) for the statistical analysis. We determined the median age of menarche and confidence intervals using survival analysis with PROC LIFETEST. We included girls who had not yet had their first period (88 participants); for girls providing only year of menarche (231), the month was imputed using the mean value for other girls of the same age in years. Probit transformation ${ }^{2}$ of the percentage of affirmative responses at each age gave almost identical results. In all, 1166 girls aged 12-16 years (1068 European, 79 South Asian, 19 other) reported their menarcheal age (response 66\%). The median menarcheal age was 12 years 11 months (95\% confidence interval 12 years 10 months to 13 years 1 month). The percentages of girls who reported having had their first period by their 10th, 11th, or 12th birthdays were $0.8,3.6$ and 21.7, respectively; $11.8 \%$ had their first period before leaving primary school. Median ages of menarche were similar in different regions (table) and did not differ by social class or ethnic group (see table on website). Non-responders closely resembled responders in age and geographical location.

\section{Comment}

The median age of menarche in contemporary British teenagers is around 13 years. In our study geographical, social, and ethnic variations were small, suggesting that non-response bias in menarcheal age was likely to be limited. Comparison with British girls born between 1950 and 1965 (table) suggests that the median menarcheal age reported here is close to or slightly below the earlier findings. Two points emerge clearly from the results. Firstly, any decrease in average menarcheal age during the past 20-30 years has been small (almost certainly less than six months), particularly when compared with the reduction of a year or more that occurred in many European countries (including Britain) between the late 19th
Regional Paediatric Endocrinology Clinic, Leeds General Infirmary, Leeds LS1 3EX

Julian H Barth consultant in chemical pathology and metabolic medicine Jenny Walker auxologist

Correspondence to: M C J Rudolf Mrudolf@ulth. northy.nhs.uk

Department of Public Health Sciences, St George's Hospital Medical School, London SW17 0RE P H Whincup professor of cardiovascular epidemiology J A Gilg research statistician K Odoki clinical research fellow D G Cook professor of epidemiology

Department of General Practice and Primary Care, Medical Sciences, Queen Mary and Westfield College, London E1 4NS S J C Taylor senior clinical lecturer Correspondence to: P H Whincup p.whincup@ sghms.ac.uk

BMJ 2001;322:1095-6 bmi.com

A figure showing age at menarche, a longer version of the table, and details of the previous studies appear on the $B M J$ 's website 